\title{
Effect of Cigarette Smoking On General Health - A Comparative Study of Different Categories of Smokers, Non Smokers and Passive Smokers
}

\author{
Dr. Mousumi Bhattacharyya ${ }^{1}$ *
}

\section{ABSTRACT}

The aim of the present investigation is to study the general health status as opined by the non smokers, controlled regular smokers, chain smokers and ex smokers and their wives. Accordingly, a group of 50 non smokers, 50 controlled regular smokers, 50 chain smokers and 50 ex smokers and their wives were selected as sample in this investigation. In this investigation differences in general health status between different categories of smokers and non smokers were studied as well as the differences between direct smokers and passive smokers also investigated by collecting data from the wives of smokers and non smokers. A general information schedule and General Health Questionnaire were used as tools in this investigation. The findings reveal that members of each group are belongs to non psychiatric category. It may be caused due to mainly for they are satisfied with the way they are carried out their task, capable of making decisions about things, been able to enjoy their normal day to day activities etc.

Keywords: Cigarette, Smoking, General Health, Smokers, Non Smokers, Passive Smokers.

The act of inhaling and exhaling the fumes of burning tobacco in cigars, cigarettes or pipes is called cigarette smoking. The dangers of smoking are not confined to the smoker himself. The non smoker person by his side is also affected by the act of smoking. Smoking is an important factor of serious health hazard. Chances of a smoker getting lung cancer are significantly more than a non-smoker. The factors such as the number of years the person has been smoking and at what age he started smoking are also very important for the smoker contracting the disease. The effects of smoking have been taken so seriously by the Indian Government that they have made it compulsory to have statutory warnings like "smoking is injurious to health" or "smoking kills" on all packs so that the new users get warned. Despite the numerous risks associated with smoking - and the numerous health benefits of quitting - more than 25 percent of adults in the

\footnotetext{
${ }^{1}$ Bangabasi College, West Bengal \& India

*Responding Author

(C) 2016 I M Bhattacharyya; licensee IJIP. This is an Open Access Research distributed under the terms of the Creative Commons Attribution License (http://creativecommons.org/licenses/by/2.0), which permits unrestricted use, distribution, and reproduction in any Medium, provided the original work is properly cited.
} 


\section{Effect of Cigarette Smoking On General Health - A Comparative Study of Different Categories of Smokers, Non Smokers and Passive Smokers}

United States, some 47 million individuals, currently smoke (Centers for Disease Control, 1996); and the figure is even higher elsewhere in the world. Unfortunately, the harmful effects of smoking do not end with the smoker. Smoking during pregnancy can have harmful effects on the developing fetus. And exposure to second-hand smoke causes an estimated 3,000 non-smokers to die of lung cancer and up to 300,000 children to suffer from respiratory tract infections annually in the United States (Centers for Disease Control, 1999). Besides this, cognitive factors appear to influence people's tendency to continue smoking. Research suggests that smokers frequently hold inaccurate perceptions about the risks of smoking (Weinstein, 1998). Smokers consistently acknowledge that smoking increases their health risks; but compared to non-smokers, smokers tend to underestimate these risks. Smokers also tend to minimize the personal relevance of the risks of smoking. They tend not to believe that they are much at risk as other smokers of becoming addicted or of suffering negative health effects. Some research reveals cultural differences in the degree of risk associated with smoking.

The non-smoker person by his side is also affected by the act of smoking. Light and intermitted smokers pose a challenge to healthcare professionals because they tend not to consider themselves "smokers" and, consequently, are under identified. This propensity not to label oneself as a smoker reinforces the belief that light and intermitted smoking does not carry significant health risks. Researchers classified smoking habits into 4 types: never; stopped; light (0-20 cigarettes/day); and heavy ( $>20$ cigarettes/day) (Brohua et al., 2005). The traditional view of Western medicine defines health as the absence of disease (Papas et al., 2004). In 1946, the United Nations established the World Health Organization (WHO) and wrote into the preamble of its constitution a modern, Western definition: "Health is a state of complete physical, mental and social well-being, and not merely the absence of disease or infirmity". This definition clearly affirms that health is a positive state and not just the absence of pathogens. Feeling good is more than not feeling bad, and research in neuroscience has confirmed the difference (Zautra, 2003). Although chronic diseases have many causes, individual behavior and lifestyle are strongly implicated in their development. Because behavior is so important for chronic disease, psychology - the science of behavior - has become involved in health care. A large part of Psychology's involvement in health care is a commitment to keeping people healthy rather than waiting to treat them after they become ill (Orleans et al., 2004). ). Cigarette smokers are generally aware of increased health risks associated with smoking, but that smokers tend to underestimate their own susceptibility to disease (Waltenbaugh and Zagummy, 2004). Many acute changes occur following one cigarette smoking even in habitual smokers. Smokers lose at least one decade of life expectancy, as compared with those who have never smoked. Cessation before the age of 40 years reduces the risk of death associated with continued smoking by about 90\%.( Jha et al.,2013). Many non-smokers find the smoke of others to be a nuisance and even irritating to their eyes and nose. In the 1980s, some evidence began to accrue that passive smoking might be a health hazard. Specifically, passive smoking has been linked to lung cancer, breast cancer, heart disease, and a variety of respiratory problems in children. The effect of 


\section{Effect of Cigarette Smoking On General Health - A Comparative Study of Different Categories of Smokers, Non Smokers and Passive Smokers}

passive smoking on lung and other cancers is difficult to determine because of the amount and duration of exposure. In general, the more environmental tobacco smoke people are exposed to and the longer the exposure, the higher the risk for cancer. Children experience the deleterious effects of environmental tobacco smoke even before they are born. Typically, those effects are not fatal, but they lead to asthma, chronic lower respiratory disease, sudden infant death syndrome (SIDS), and other disorders that affect children (Cantani and Miceraq, 2005). The dangers of smoking are not confined to the smoker himself. The non-smoker persons by his side are also affected by the act of smoking. Passive smoking is also known as second-hand smoking. Whether it is active or passive smoking, harmful effects of smoking are numerous. Smoke containing nicotine is inhaled into the lungs and the nicotine reaches into the brain in just six seconds. Most of the chemicals inhaled in cigarette smoke stay in the lungs. Waltenbaugh and Zagummy (2004) studied that cigarette smokers are generally aware of increased health risks associated with smoking, but that smokers tend to underestimate their own susceptibility to disease. Considering the above, the present investigation has been designed to study the general health status of a group of smokers and non smokers and their wives (as passive smokers) of different areas of Kolkata city.

\section{OBJECTIVES}

1) To study the general health status of non-smokers.

2) To study the general health status of different categories of smokers.

3) To study the general health status of ex-smokers.

4) To study the health status of wives of chain smokers and controlled regular smokers as they are passive smokers also.

5) To study the general health of the wives of ex smokers.

\section{Hypotheses:}

Hypothesis - I: General health of the chain smokers is poor than that of the controlled regular smokers.

Hypothesis - II: non smokers have comparatively better health status than that of the controlled regular smokers and chain smokers.

Hypothesis - III: ex smokers have comparatively poor health status than that of the non smokers.

Hypothesis - IV: wives of non smokers have comparatively good health status than that of the wives of the chain smokers and controlled regular smokers

Hypothesis V: wives of controlled regular smokers have good health status than that of the wives of the chain smokers

Hypothesis VI: wives of non smokers possess comparatively better health status than that of the wives of ex smokers. 


\section{METHODS}

\section{Sample}

A group of 200 (50 non-smokers, 50 controlled regular smokers, 50 chain smokers and 50 exsmokers) employed married couples aged between 30 yrs to 50 yrs of age whose minimum educational qualification is graduation were selected as sample in this investigation.

\section{Tools Used}

1. General information schedule - It consists of items like, name, age, educational qualification, designation and monthly income.

2. General Health Questionnaire - It is designed by Goldberg and Hiller (1979) for detecting short-term changes in mental health among respondents. GHQ containing 28 items was derived from factor analysis of GHQ 60. It consists of four sub-scales from somatic symptoms, anxiety, insomnia, social dysfunction and severe depression. Its sensitivity was found to be 0.80 and specially 0.88 .

\section{Administration, scoring and statistical treatment}

In consultation with the selected subjects, non smokers, controlled regular smokers, chain smokers and ex-smokers and their wives, a tentative programme schedule was developed for fixing up probable dates and time of the test sessions. Data were collected by giving proper instruction. After collecting the data after a short time all the data were properly scored and scrutinized. Scoring and tabulation were done for all four categories of subjects, viz., non smokers, controlled regular smokers, chain smokers and ex-smokers and their wives. All the couples are belongs to the different areas of Kolkata city. For General information schedule, frequencies and percentages were calculated. In case of General Health Questionnaire, respective scoring key was used to score the data. Mean and S.D. were calculated. Comparisons were made by applying t-test and One way ANOVA. 


\section{Effect of Cigarette Smoking On General Health - A Comparative Study of Different Categories of Smokers, Non Smokers and Passive Smokers}

\section{RESULT AND INTERPRETATION:}

The general characteristic data inserted in Table 1 reveals the characteristic features of the subject, under study

\section{Table 1: general characteristic features of the subject}

\begin{tabular}{|c|c|c|c|c|c|c|c|c|c|c|c|c|c|c|c|c|}
\hline \multirow{2}{*}{$\begin{array}{l}\text { Characteristics } \\
\text { Age }\end{array}$} & \multicolumn{2}{|c|}{$\begin{array}{l}\text { (Group A) } \\
\text { husbands }\end{array}$} & \multicolumn{2}{|c|}{$\begin{array}{l}\text { (Group A) } \\
\text { wives }\end{array}$} & \multicolumn{2}{|c|}{$\begin{array}{l}\text { (Group B) } \\
\text { husbands }\end{array}$} & \multicolumn{2}{|c|}{$\begin{array}{l}\text { (Group B) } \\
\text { wives }\end{array}$} & \multicolumn{2}{|c|}{$\begin{array}{l}\text { (Group C) } \\
\text { husbands }\end{array}$} & \multicolumn{2}{|c|}{$\begin{array}{l}\text { (Group C) } \\
\text { wives }\end{array}$} & \multicolumn{2}{|c|}{$\begin{array}{l}\text { (Group D) } \\
\text { husbands }\end{array}$} & \multicolumn{2}{|c|}{$\begin{array}{l}\text { (Group D) } \\
\text { wives }\end{array}$} \\
\hline & $\mathrm{F}$ & $\%$ & $\mathrm{f}$ & $\%$ & $\mathrm{f}$ & $\%$ & $\mathrm{f}$ & $\%$ & $\mathrm{f}$ & $\%$ & $\mathrm{f}$ & $\%$ & $\mathrm{f}$ & $\%$ & f & $\%$ \\
\hline $30-34$ & 11 & 22.00 & 15 & 30.00 & 10 & 20.00 & 14 & 28.00 & 17 & 34.00 & 13 & 26.00 & 12 & 24.00 & 15 & 30.00 \\
\hline $35-39$ & 13 & 26.00 & 15 & 30.00 & 17 & 34.00 & 15 & 30.00 & 15 & 30.00 & 16 & 32.00 & 18 & 36.00 & 14 & 28.00 \\
\hline $40-44$ & 15 & 30.00 & 11 & 22.00 & 16 & 32.00 & 10 & 20.00 & 10 & 20.00 & 13 & 26.00 & 09 & 18.00 & 12 & 24.00 \\
\hline $45-49$ & 09 & 18.00 & 08 & 16.00 & 07 & 14.00 & 09 & 18.00 & 06 & 12.00 & 07 & 14.00 & 10 & 20.00 & 08 & 16.00 \\
\hline $50-54$ & 02 & 04.00 & 01 & 2.00 & 00 & 00.00 & 02 & 04.00 & 02 & 04.00 & 01 & 2.00 & 01 & 02.00 & 01 & 2.00 \\
\hline $\begin{array}{l}\text { Educational } \\
\text { Qualification }\end{array}$ & $\mathrm{F}$ & $\%$ & f & $\%$ & f & $\%$ & $\mathrm{f}$ & $\%$ & $\mathrm{f}$ & $\%$ & $\mathrm{f}$ & $\%$ & $\mathrm{f}$ & $\%$ & $\mathrm{f}$ & $\%$ \\
\hline a) Graduate & 30 & 60.00 & 32 & 64.00 & 27 & 54.00 & 26 & 52.00 & 26 & 52.00 & 25 & 50.00 & 28 & 56.00 & 22 & 44.00 \\
\hline $\begin{array}{l}\text { b) Graduate } \\
\text { c) and others }\end{array}$ & 20 & 40.00 & 18 & 36.00 & 23 & 46.00 & 24 & 48.00 & 24 & 48.00 & 25 & 50.00 & 22 & 44.00 & 28 & 56.00 \\
\hline Occupational Status & $\mathrm{F}$ & $\%$ & f & $\%$ & f & $\%$ & $\mathrm{f}$ & $\%$ & $\mathrm{f}$ & $\%$ & $\mathrm{f}$ & $\%$ & $\mathrm{f}$ & $\%$ & $\mathrm{f}$ & $\%$ \\
\hline a) Occupied & 50 & 100 & 26 & 32.00 & 50 & 100 & 23 & 46.00 & 50 & 100 & 25 & 50.00 & 50 & 100 & 24 & 48.00 \\
\hline b) Housewives & 00 & 00 & 24 & 48.00 & 00 & 00 & 27 & 54.00 & 00 & 00 & 25 & 50.00 & 00 & 00 & 26 & 52.00 \\
\hline
\end{tabular}

Table 2, A : General health of four group of subjects (mean score)

\begin{tabular}{|c|c|c|c|c|c|c|c|c|}
\hline & \multicolumn{2}{|l|}{ Group A } & \multicolumn{2}{|l|}{ Group B } & \multicolumn{2}{|l|}{ Group C } & \multicolumn{2}{|l|}{ Group D } \\
\hline & $\begin{array}{l}\text { Husbands } \\
(\mathrm{N}=50)\end{array}$ & $\begin{array}{l}\text { Wives } \\
(\mathrm{N}=50)\end{array}$ & $\begin{array}{l}\text { Husbands } \\
(\mathrm{N}=50)\end{array}$ & $\begin{array}{l}\text { Wives } \\
(\mathrm{N}=\mathbf{5 0})\end{array}$ & $\begin{array}{l}\text { Husbands } \\
(\mathrm{N}=50)\end{array}$ & $\begin{array}{l}\text { Wives } \\
(\mathrm{N}=50)\end{array}$ & $\begin{array}{l}\text { Husbands } \\
(\mathrm{N}=50)\end{array}$ & $\begin{array}{l}\text { Wives } \\
(\mathrm{N}=50)\end{array}$ \\
\hline Mean & 3.78 & 3.02 & 2.62 & 3.58 & 2.18 & 1.98 & 1.34 & 1.70 \\
\hline S.D. & 1.12 & 1.82 & 1.68 & 1.97 & 0.92 & 1.24 & 1.12 & 1.32 \\
\hline
\end{tabular}

- 0 - 4 = Non psychiatric

- 5 onwards $=$ Psychiatric case

From the above table it is clear that the mean value is highest for the husbands of Group A i.e. chain a smoker which indicates poor general health status than that of the males of other groups. After chain smokers the second highest mean value for general health is of the controlled regular smoker which is higher than non smokers and ex smokers respectively. So it is clear from the mean values that smoking causes health hazards. But in case of ex smokers it is clear that their mean value of general health score is lower than non smokers also. Here we can say that many of smokers quit from the habit of smoking mainly due to health problems of their own or their near ones. So, after cessation they feel good and they perceive that their health condition becomes far better than previous days though S.D. value are higher in case of ex smokers than non smokers.

In case of wives who acted as passive smoker in this investigation, it is seen that mean value for wives of controlled regular smokers is higher than that of the other groups as it indicates poor health status. Findings in case of wives of ex smokers is like their husbands as wives of ex 


\section{Effect of Cigarette Smoking On General Health - A Comparative Study of Different Categories of Smokers, Non Smokers and Passive Smokers}

smokers possess good health status than non smokers because they perceive their successful smoking cessation as the cause of their health improvement.

Table 2B : Group-wise comparison in terms of general health scores

\begin{tabular}{|l|l|l|l|l|l|l|}
\hline & A vs. B & A vs. C & A vs. D & B vs. C & B vs. D & C vs. D \\
\hline Husbands & $4.69 * *$ & $9.00^{* *}$ & $12.00^{* *}$ & $1.63^{*}$ & $4.41^{* *}$ & $4.20^{* *}$ \\
\hline Wives & $1.47^{*}$ & $3.35^{* *}$ & $4.13^{* *}$ & $4.85^{* *}$ & $5.53^{* *}$ & $1.08^{*}$ \\
\hline
\end{tabular}

\section{* Difference is insignificant \\ $* * \mathbf{p}<0.01$}

Data inserted in Table - 2A, 2B reveals that all the subjects belong to non-psychiatric group. Analysis of data also reveals that general health of the smokers are comparatively poor than that of the other groups. It can further be said that, after leaving the habit of smoking, ex-smokers became more health conscious than that of the previous stage. Previous findings revealed that cigarette smokers are generally aware of increased health risks associated with smoking, but that smokers tend to underestimate their own susceptibility to disease (Waltenbaugh, et al., 2004).

From the result it is clear that general health status is very poor in case of chain smokers in comparison the controlled regular smokers. Thus the Hypothesis I, which postulates "General health of the chain smokers is poor than that of the controlled regular smokers.' - is accepted as the significant difference found between group A and group B. Hypothesis - II which postulates "non smokers have comparatively better health status than that of the controlled regular smokers and chain smokers” is accepted as the significant difference found between group A and C. Hypothesis - III which states that "ex smokers has comparatively poor health status than that of the non smokers” is rejected though significant difference was found. It happened due to that ex smokers feel more comfortable health status after quitting as good health was one of the important motivation behind quit smoking. Cessation before the age of 40 years reduces the risk of death associated with continued smoking by about 90\%.( Jha et al.,2013). It can be reffered as the reason for why ex smokers health ststus is much better thgan other groups of smokers. It can be also reffered that Waltenbaugh and Zagummy (2004) studied that cigarette smokers are generally aware of increased health risks associated with smoking. F ratio for smokers is significant at 0.01 level which is 35.23. Hypothesis - IV: wives of non smokers have comparatively good health status than that of the wives of the chain smokers and controlled regular smokers" is accepted as the significant difference was found. Hypothesis V: “wives of controlled regular smokers have good health status than that of the wives of the chain smokers" is rejected as the significant difference was not found. It may be caused due to the fact that wives of controlled regular smokers suffers from more tension of increasing the habit of smoking of their husbands or as they are very susceptible of passive smoking their husbands bound to control their habit of smoking. Hypothesis VI: “wives of non smokers possess comparatively better health status than that of the wives of ex smokers" is rejected as the mean value states that 


\section{Effect of Cigarette Smoking On General Health - A Comparative Study of Different Categories of Smokers, Non Smokers and Passive Smokers}

wives ex smokers scored low than that of the wives of non smokers. F ratio for wives is 13.12 which is significant at 0.01 level.

\section{APPLICATIVE POTENTIAL OF THE PRESENT STUDY}

1. The findings of the present study may help to create more health consciousness among the chain smokers and controlled regular smokers about cigarette smoking which has been revealed from the findings by applying different tools.

2. The findings of the study may also help to know about the ill-effects of direct smoking and passive smoking.

3. From this study it has been revealed that smokers can improve their health status by smoking cessation.

4. Overall findings of the present research work in connection with different aspects of life may help the smokers to maintain a good and healthy life physically.

\section{CONCLUDING REMARKS}

Considering the above, the present investigation has been designed to study the impact of direct and passive smoking as expressed by a group of chain smokers, controlled regular smokers, nonsmokers and ex-smokers and their wives. Accordingly, a group of 50 chain smokers, 50 from controlled regular smokers, 50 non-smokers and 50 ex-smokers and their wives were selected as subjects across Kolkata City. Smokers are using only cigarettes from the different products of tobacco. Accordingly, six hypotheses were formulated for this present investigation. A General Information Schedule, General health questionnaire were administered to the subjects by giving proper instruction. Appropriate descriptive statistics (frequency, percentage, mean and standard deviation) were calculated for each group separately. Comparisons were made by applying t-test and ANOVA.

The findings of the present study may help to create more consciousness among the smokers about cigarette smoking. As it has also been revealed that poor general health was found among the chain smokers and controlled regular smokers than that of the non smokers and ex smokers. So for healthy living quitting the habit of smoking is desirable. Wives of smokers possess poor general health as they are passive smokers than that of the non smokers and ex smokers. From this study it is also clear that for the family members health it is very necessary to quit smoking.

\section{REFERENCES}

Brohua, X., Tromp, D., Hordijk, G.J., Winnubst, J., De Leeuw, R. (2005). Role of alcohol and smoking in diagnostic delay of head and neck cancer patients. Acta Otolaryngol, 125(5), 552-6.

Cantani, A. and Miceraq, M. (2005). Epidemiology of passive smoke: A prospective study in 589 children. European Review for Medical and Pharmacological Sciences, 9, 23-30. 


\section{Effect of Cigarette Smoking On General Health - A Comparative Study of Different Categories of Smokers, Non Smokers and Passive Smokers}

Center for Disease Control (1999). At-a-glance 1999: Targetting Tobacco Use; The Nations Leading Cause of Death, Atlanta, (www.cdc.gov/tobacco/oshaag.htm).

Center for Disease Control. (1996). Cigarette smoking among adults: United States, 1994. Morbidity and Mortality Weekly Report, 45, 588-590.

Jha, P.,M., Ramasundarahettige, C., Landsman, V. Rostron, B., Thun, M., Anderson, R.N.,, Tim McAfee, and Peto, R., .(2013). 21st-Century Hazards of Smoking and Benefits of Cessation in the United States. The New England journal of Medicine 2013; 368:341-350 January 24, 2013 DOI: 10.1056/NEJMsa1211128.

Orleans, C.T., Ulmer, C.C., Gruman, J.C. (2004). The role of behavioural factors in achieving national health outcomes. In Frank, R.J., Baum,A., Wallander, J.L. (Eds). Handbook of clinical health psychology, Washington, DC: American Psychological Association, 3, 465-499.

Papas, R.K., Belar, C.D., Rozensky, R.H. (2004). The practice of clinical health psychology. Professional issues. In Frank, R.J., Baum,A., Wallander, J.L. (Eds). Handbook of clinical health psychology, 3, 293-319.Washington, DC: American Psychological Association.

Waltenbaugh, A.W., Zagummy, M.J. (2004). optimistic bias and perceived control among cigarette smokers. Journal of Alcohol and Drug Education, 47(3), 20-33.

Weinstein, N.D. (1998). Accuracy of Smokers' risk perceptions. Annals of Behavioural Medicine, 20, 135-140.

Zautra, A.J. (2003). Emotions, stress, and health. New York: Oxford University Press. (www.books.google.com). 